\title{
FEATURE \\ An integrated approach to grazingland ecological assessments and management interpretations
}

\author{
David Toledo, Matt Sanderson, Jeffrey Herrick, and Sarah Goslee
}

I $\mathrm{n}$ the United States, grazinglands have been separated into categories such as rangelands and pasturelands and have traditionally been assessed using different methods and indicators. The term grazingland refers to areas producing forage from native or introduced plants and harvested directly by animals without reference to land tenure or other land uses (Allen et al. 2011). The largest area of grazingland in the United States occurs west of the 100th meridian, in water-limited rangelands (Briske 2011). The eastern portion of the country, where water is not a limiting factor, contains substantial areas of improved pastures (Sanderson et al. 2012). Together, these grazinglands represent a substantial proportion, nearly $22 \%$ (Jin et al. 2013), of agricultural lands in the United States (figure 1) and contribute many ecosystem goods and services that help support human well-being (Nelson et al. 2012). When taking into account the dichotomy in grazingland terminology, it is important to note that for some parts of the United States, and many parts of the world, the difference between pasturelands and grazinglands is less clear and land considered a pasture to some might be considered an intensively managed rangeland to others. Here we follow the Allen et al. (2011) definitions for pastureland and rangeland where pastureland is defined as "land (and the vegetation growing on it) devoted to the production of introduced or indigenous forage for harvest by grazing, cutting, or both. Usually managed to arrest successional processes." Rangeland is defined as "land on which the indig-

David Toledo is research rangeland management specialist at the USDA Agricultural Research Service Northern Great Plains Research Laboratory, Mandan, North Dakota. Matt Sanderson is research leader at the USDA Agricultural Research Service Northern Great Plains Research Laboratory, Mandan, North Dakota. Jeffrey Herrick is a research soil scientist at the USDA Agricultural Research Service Jornada Experimental Range, Las Cruces, New Mexico. Sarah Goslee is an ecologist at the USDA Agricultural Research Service Pasture Systems and Watershed Management Research Unit, University Park, Pennsylvania. enous vegetation (climax or subclimax) is predominantly grasses, grass-like plants, forbs, or shrubs that are grazed or have the potential to be grazed, and which is used as a natural ecosystem for the production of grazing livestock and wildlife."

Rangeland health assessments consist of evaluating how well ecological processes, such as hydrologic cycling, energy flow, and nutrient cycling, are functioning at a site. The most commonly used rangeland health assessment protocol on US rangelands is the Interpreting Indicators of Rangeland Health (IIRH) assessment (Pellant et al. 2005; Toevs et al. 2011). The IIRH assessment uses 17 indicators (table 1) to rate the following three attributes of rangeland health:

1. Soil and site stability, which refers to "the capacity of an area to limit redistribution and loss of soil resources by wind and water."

2. Hydrologic function, which refers to "the capacity of an area to capture, store, and safely release water from rainfall, run-on, and snowmelt; to resist a reduction in this capacity; and to recover this capacity when a reduction does occur."

3. Biotic integrity, which refers to "the capacity of the biotic community to support ecological processes within the normal range of variability expected for the site, to resist a loss in the capacity to support these processes, and to recover this capacity when losses do occur. The biotic community includes plants, animals, and microorganisms occurring both above and below ground" (Pellant et al. 2005).

A major weakness of IIRH is that, unlike the Pasture Condition Score (PCS), it was never designed to provide management interpretations; users are provided little guidance on how to apply evaluations to management, despite the fact that the results are clearly relevant to management.

The PCS system was developed by the USDA Natural Resources Conservation Service as a monitoring and management tool for pasturelands (Cosgrove et al. 2001). Pasture condition refers to "the status of the plant community and the soil in a pasture in relation to its highest possible condition

\section{Figure 1}

Grazingland cover in the continental United States based on the 2011 National Land Cover Database (Jin et al. 2013).

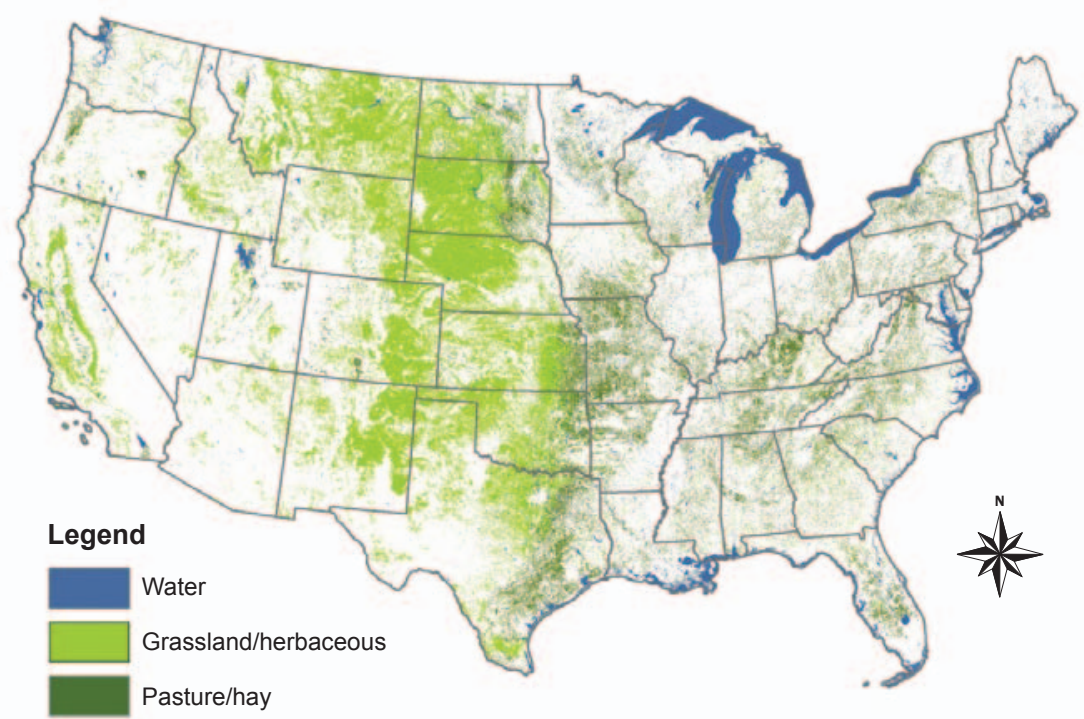




\section{Table 1}

Indicators and brief description for Interpreting Indicators of Rangeland Health (Pellant et al. 2005).

\begin{tabular}{l} 
Indicator \\
\hline Rills \\
Water-flow Patterns \\
Pedestals and/or terracettes \\
Percentage bare ground \\
Compaction layer \\
Gullies \\
Soil surface resistance to erosion \\
Wind-scoured, blowouts, and/or \\
deposition areas
\end{tabular}

Functional/structural groups

Plant mortality/decadence

Litter amount

Annual production

Invasive plants

Reproductive capability of perennial plants

\section{Description}

Sidecut linear features formed through complex interactions between raindrops, overland flow, and the characteristics of the soil surface (Bryan 1987).

The path that water takes as it moves across the soil surface during overland flow. These patterns are generally evidenced by litter, soil or gravel redistribution, or pedestalling of vegetation or stones that break the flow of water (Morgan 1986) and are rarely continuous.

Rocks or plants that appear elevated as a result of soil loss by wind or water erosion.

Exposed mineral or organic soil that is susceptible to rain drop splash erosion, the initial form of most water-related erosion (Morgan 1986).

A channel with a headcut that has been cut into the soil by moving water.

Wind eroded areas where the finer particles of the topsoil have blown away, or in some cases areas where finer particles have been deposited behind obstacles that slow wind velocity.

The degree and amount of litter movement.

Resistance of the surface of the soil to erosion.

The loss or degradation of part or all of the soil surface layer or horizon.

The distribution of the amount and type of vegetation and its effects on infiltration and erosion rates.

Near-surface layer of dense soil caused by repeated impacts on or disturbances of the soil surface.

A suite of species that are grouped together. Both the presence of functional groups and the number of species within the groups have a significant effect on ecosystem processes (Tilman et al. 1997).

The proportion of dead or decadent (e.g., moribund or dying) to young or mature plants in the community, relative to that expected for the site under normal disturbance regimes.

Any dead plant material that is detached from the base of the plant.

As used in IIRH, the net quantity of above-ground vascular plant material produced within a year.

Plants that are not part of (if exotic), or are a minor component of (if native), the original plant community or communities that have the potential to become a dominant or codominant species on the site if their future establishment and growth is not actively controlled by management interventions.

An assessment of inflorescence production for sexually reproducing plants and clonal production for vegetatively reproducing plants, relative to what should be expected. under ideal management." Ten indicators of vegetation and soil status (table 2) are rated on a one to five scale and are summed to give an aggregate score, which is evaluated and interpreted together with potential causative factors to make management rec- ommendations (Sanderson et al. 2009). A major weakness of the PCS is that it lacks site-specific reference conditions with which to make assessments.

Since the National Research Council Rangeland Health Report (NRC 1994) two decades ago, federal natural resourcerelated agencies have gradually developed and adopted consistent protocols through formal and informal interagency consultation supported by research. The US Department of Interior's Bureau of Land Management has adopted the National Resources Inventory (NRI) protocols for national implementation through the Assessment, Inventory and Monitoring strategy (Toevs et al. 2011), and many other agencies are gradually adopting these methods as part of their monitoring programs at the local and regional level. The NRI now has over 90\% consistency between pasture and range on quantitative protocols. Methods consistency has been reached in methods such as line-point intercept, canopy gap intercept, field soil stability test, vegetation height, and rangeland health assessment.

The NRI effort on pastureland began in 2010 and was fully implemented across the United States in 2013. Pastureland assessment methods such as the PCS provide an assessment of a site for livestock management purposes but miss some important ecological information, such as how water might be moving into, through, or out of a site. This ecological information is captured by IIRH. Evaluating the potential for an integrated assessment tool based on the strength of each of the above methods is critical since the most important lands to evaluate are often those where land use/land cover is dynamic (shifting between pasture, range, and crop), and resource allocation and decision making at the national scale needs to be based on comparable metrics.

The Pellant et al. (2005) IIRH and the Cosgrove et al. (2001) PCS have been widely used and accepted within the rangeland and livestock management communities, but direct comparisons of the results from these methods are not possible, and in some cases might be redundant. We present an integrated grazingland assessment strategy supported by ecology and management that provides a common approach to gather information at the national scale.

\section{METHODS}

Qualitative Methods. We report results from an online focus group consisting of 
19 experts in IIRH, PCS, or both methods. The focus group was composed by using a snowball-network sampling approach, which consisted of finding an initial group of 3 experts in the subject and asking them to refer others who could provide valuable input. We identified as key actors those individuals who had field experience using either method or those who had contributed to the theoretical development of these different assessment tools. We used a snowball network sampling approach to efficiently provide in-depth descriptive and explorative qualitative data (Bernard 2006). To provide guidance to this focus group, we developed a set of open-ended questions covering specific topics, such as method commonalities, differences, potential for unification, and potential adoption of a new unified approach.

Quantitative Methods. We conducted assessments using the IIRH protocol (Pellant et al. 2005) and the PCS protocol at four different sites in the Great Plains region of the United States. Sites included the Standing Rock Sioux Reservation (SRSR) and USDA Agricultural Research Service (ARS) Northern Great Plains Research Lab (NGPRL) in the northern mixed grass prairie, the USDA ARS Central Plains Experimental Range (CPER) in the short grass steppe, and the USDA ARS Livestock and Range Research Laboratory (LRRL) in the mixed grass prairie. Sites represent areas dominated by rangelands (SRSR and CPER) and areas with both pasture and rangelands (NGPRL and LRRL). At each site we selected sampling locations based on vegetation type and grazing intensity so we could encompass the vegetation variation present at each sampling location. For IIRH we provided numerical values in a Likert scale from one to five, where one represents extreme to total departure from reference condition and five represents none to slight departure. PCS indicators range from one to five, where one represents degraded areas and five represents areas in excellent condition. We inverted the values of the PCS protocol for analysis purposes to make comparisons and interpretations more intuitive. IIRH indicators that were identified as related to the erosion indicator in PCS were analyzed

\section{Table 2}

Indicators and brief description for Pasture Condition Scoring (Cosgrove et al. 2001).

\begin{tabular}{|c|c|}
\hline Indicator & Description \\
\hline Percentage desirable plants & $\begin{array}{l}\text { Percentage of plants that livestock would readily consume, } \\
\text { are persistent, and provide high tonnage and quality } \\
\text { for a significant part of the growing season. }\end{array}$ \\
\hline Percentage plant cover & The percentage of the soil surface covered by plants. \\
\hline Plant diversity & $\begin{array}{l}\text { The number of different forage plants that are well repre- } \\
\text { sented ( } 20 \% \text { or more of plant cover) in a pasture. }\end{array}$ \\
\hline Plant residue & $\begin{array}{l}\text { Percentage of dead plant material (standing dead or thatch) } \\
\text { in a pasture. }\end{array}$ \\
\hline Plant vigor & $\begin{array}{l}\text { Overall color, size, rate of regrowth following harvest, and } \\
\text { productivity of desirable and intermediate plant species. }\end{array}$ \\
\hline Percent legume & Percentage of legumes present as total air dry weight. \\
\hline Uniformity of use & $\begin{array}{l}\text { Uniformity of animal grazing patterns. Uniform grazing results } \\
\text { in all desirable and intermediate species being grazed to a } \\
\text { similar height. }\end{array}$ \\
\hline Livestock concentration areas & $\begin{array}{l}\text { Places in pastures where livestock return frequently and linger } \\
\text { to be near water, feed, mineral or salt, or shelter, or to be } \\
\text { in shade. }\end{array}$ \\
\hline Soil compaction & $\begin{array}{l}\text { Increased bulk density (weight per volume of soil) of layers } \\
\text { at } 2.5 \mathrm{~cm}(1 \mathrm{in}) \text { increments to plow depth. Can also be } \\
\text { detected in the field using a soil probe, metal rod, or knife. }\end{array}$ \\
\hline Erosion & $\begin{array}{l}\text { Soil loss cause by wind or water. Evaluated in terms of wind, sheet, } \\
\text { and rill erosion or streambank, shoreline, and gully erosion. }\end{array}$ \\
\hline
\end{tabular}

individually and were also combined and examined for internal consistency using Cronbach's alpha and confirmatory factor analysis. Cronbach's alpha values greater than 0.7 generally indicate that the components of an index are reliably related to each other (Foster 2001). We compared each pair of indicators that our focus group identified as being comparable using regression analysis.

\section{EVALUATING NEEDS FOR AN INTEGRATED ASSESSMENT}

Discussions from a focus group consisting of 19 national experts experienced at applying rangeland health and pasture condition scoring methods suggest that most indicators in each of the two protocols could be combined into one common approach, but some indicator combinations were specific to each grazingland type (rangeland or pastureland). Quantitative comparisons of erosion indicators together with indicators related to soil compaction, plant mortality and plant vigor, and litter amount and plant residue (table 3) show statistically significant results. However, the strength of those relationships was not as high as predicted.
It was especially striking to see that erosion could be rated very differently by the two methods even at the same site, where it should be both quantitatively and qualitatively identical. Identified biases based on methodology call for a need to account for differences in results from these two methods. There is a need to capture the best from both the rangeland and pastureland assessment methods while taking into account ecosystem attributes and management objectives of the grazinglands where these methods are usually applied.

The focus group also identified indicators that have no close matches between IIRH and PCS but are important in terms of ecology and management interpretation. These indicators included, but were not limited to, soil surface resistance to erosion, plant community composition and distribution relative to infiltration, uniformity of use, and livestock concentration areas.

\section{ECOLOGICAL AND MANAGEMENT INTERPRETATIONS}

The IIRH technique uses rangeland health evaluation matrices, which rate an area based on the degree of departure from ecologi- 


\section{Table 3}

Regression analysis on field measurement of paired Interpreting Indicators of Rangeland Health (IIRH) and Pasture Condition Score (PCS) indicators that were described as measuring similar attributes by the focus group.

\begin{tabular}{lllll}
\hline IIRH indicator & PCS indicator & $\begin{array}{l}\text { Focus group level } \\
\text { of agreement } \\
\text { with similarity }\end{array}$ & $\boldsymbol{r}^{2}$ & p-value \\
\hline Erosion index* & Erosion & N/A & 0.45 & $<0.0001$ \\
Compaction & Compaction & Strongly agree & 0.31 & $<0.0001$ \\
Mortality & Plant vigor & Strongly disagree & 0.42 & $<0.0001$ \\
Litter & Plant residue & Strongly agree & 0.21 & 0.0029 \\
\hline
\end{tabular}

* Best possible erosion index determined by a confirmatory factor analysis. Index was calculated using IIRH indicators for rills and gullies.

cal potential for a particular ecological site. Ecological potential is defined to include natural occurring spatial and temporal variability. This is a well-established assessment tool for rangelands and is sensitive to changes in ecosystem attributes related to soil and site stability, hydrologic function, and biotic integrity at a site (Duniway et al. 2010; Toevs et al. 2011). Pasture Condition Scores are also rated using an evaluation matrix, but the PCS matrix is based on what an ideal pasture should look like with no site-specific adjustment for variation in ecological potential (Sanderson 2014). A key difference in the conceptual frameworks used to develop these two methodologies is that IIRH clearly excludes from the assessment confounding factors that determine site potential. It also excludes management inputs and therefore has no way to document instances where ecological potential is exceeded with management. PCS fails to recognize differences in site potential, which makes results more difficult to interpret for management as there is no way to determine whether a less than optimal rating is due to inherent site limitations or degradation (Sanderson 2014). It does however recognize that management inputs can allow a site to exceed its potential, and is more sensitive to changes in site conditions that are easily modified by management, such as soil fertility and $\mathrm{pH}$.

\section{A PROPOSAL FOR AN INTEGRATED APPROACH}

We propose that the strengths of the two protocols be integrated as follows:

1. Adoption of a single protocol for ecological assessments relative to site potential. IIRH could serve this role as it was specifically designed to be adapted to a broad range of conditions, including grasslands, shrublands, savannas, wet meadows, and subirrigated riparian areas. The protocol is adapted to each unique ecological site and allows indicators to be evaluated based on a "preponderance of evidence" weighting system. Individual indicators can be emphasized or deemphasized when completing the three attribute ratings based on (a) relevance to the site and (b) confidence of the evaluator in the indicator at a particular point in time. For example the "gully" indicator is generally ignored on lake plains. This protocol also allows for the creation of detailed site-specific evaluation matrices based on ecological site potential that helps fine-tune assessments to a particular ecological site and reduce evaluator bias.

2. Development of a management interpretation protocol based on PCS. This would allow evaluators to use assessment results to make interpretations regarding management based on sitespecific management attributes that can potentially exceed the ecological potential of a site. Site-specific management interpretations derived from PCS could be based on management type and would help determine pasture potential under different management regimes. By allowing for differences in management potential and management type based on site-specific indicators, this tool would serve to optimize management for each site being evaluated.

\section{SUMMARY AND CONCLUSIONS}

Developing and applying an integrated grazingland assessment tool that can be used to generate scientifically supported data that meet the needs of a wide range of users will lead to more cost-effective monitoring programs. By developing an integrated approach that incorporates the lessons learned from this study, assessments will be able to provide comparable metrics for all grazinglands, thus aiding decision making at the national scale. Optimization of grazingland evaluation approaches based on land potential and land use with the incorporation of ecological site and rangeland health concepts would also provide realistic management scenarios.

\section{ACKNOWLEDGEMENTS}

We would like to thank our focus group participants who provided valuable insight on method unification. This work was supported by funds from a Conservation Effects Assessment Project jointly funded by the USDA Natural Resources Conservation Service and the Agricultural Research Service.

\section{REFERENCES}

Allen, V.G., C. Batello, E.J. Berretta, J. Hodgson, M. Kothmann, X. Li, J. McIvor, J. Milne, C. Morris, A. Peeters, and M. Sanderson. 2011. An international terminology for grazing lands and grazing animals. Grass Forage Science 66:2-28.

Bernard, H.R. 2006. Research methods in anthropology: Qualitative and quantitative approaches. Lanham, MD: Altamira Press.

Briske, D.D. (ed). 2011. Conservation Benefits of Rangeland Practices: Assessment, Recommendations, and Knowledge Gaps. Washington, DC: United States Department of Agriculture, Natural Resources Conservation Service

Bryan, R.B. 1987. Processes and significance of rill development. In Rill Erosion: Processes and Significance, ed. R.B. Bryan. Catena Supplement, 8.Verlag, Germany: Catena.

Cosgrove, D., D. Undersander, and J.B. Cropper. 2001. Guide to Pasture Condition Scoring. Ft. Worth, TX: USDA Natural Resources Conservation Service Grazing Lands Technical Institute.

Duniway, M.C., J.E. Herrick, D.A. Pyke, and D. Toledo. 2010. Assessing transportation infrastructure impacts on rangelands: Test of a standard rangeland assessment protocol. Rangeland Ecology \& Management 63(5):524-536. 
Foster, J.J. 2001. Data Analysis Using SPSS for Windows: A Beginner's Guide. Thousand Oaks, CA: Sage.

Jin, S., L. Yang, P. Danielson, C. Homer, J. Fry, and G. Xian. 2013. A comprehensive change detection method for updating the National Land Cover Database to circa 2011. Remote Sensing of Environment 132:159 -175.

Morgan, R.P.C. 1986. Soil Erosion and Conservation, Ed. D.A. Davidson. New York: Longman Scientific and Technical.

NRC (National Research Council). 1994. Rangeland health: New Methods to Classify, Inventory, and Monitor Rangelands. Washington, DC: National Academy Press.

Nelson, C.J., D.J. Barker, L.E. Sollenberger, and C.W. Wood. 2012. Executive summary: New foundations for conservation standards. In Conservation Outcomes from Pastureland and Hayland Practices: Assessment, Recommendations, and Knowledge Gaps, ed. C.J. Nelson. Lawrence, KS: Allen Press.

Pellant, M., P. Shaver, D.A. Pyke, and J.E. Herrick. 2005. Interpreting indicators of rangeland health, version 4. Technical Reference 1734-6. Denver, CO: US Department of the Interior, Bureau of Land Management, National Science and Technology Center.

Sanderson, M.A., S.C. Goslee, J. Gonet, and R. Stout. 2009. Pasture monitoring at a farm scale with the USDA NRCS pasture condition score system. Journal of Soil and Water Conservation 64(6):423-433.

Sanderson, M.A., L.W. Jolley, and J.P. Dobrowolski. 2012. Pastureland and hayland in the USA: Land resources, conservation practices, and ecosystem services. In Conservation Outcomes from Pastureland and Hayland Practices: Assessment, Recommendations, and Knowledge Gaps, ed. C.J. Nelson. Lawrence, Kansas: Allen Press.

Sanderson, M.A. 2014. Evaluating the USDA-NRCS pasture condition score system with weighted indicators. Ecological Indicators 41:183-186.

Tilman, D., J. Knops, D. Wedin, P. Reich, M. Ritchie, and E. Siemann 1997. The influence of functional diversity and composition on ecosystem processes. Science 277:1300-1302.

Toevs, G.R., J.W. Karl, J.J. Taylor, C.S. Spurrier, M.S. Karl, M.R.Bobo, and J.E. Herrick. 2011. Consistent indicators and methods and a scalable sample design to meet assessment, inventory, and monitoring information needs across scales. Rangelands 33(4):14-20. 